\title{
RAZGLEDI
}

\section{PODEŽELSKI TURIZEM IN SOCIALNI KAPITAL V SLOVENIJI (PRIMER VASI V OBČINI CERKNO)}

\author{
AVTORICI \\ mag. Renata Mavri \\ Biotehniški center Naklo, Strahinj 99, SI - 4202 Naklo, Slovenija \\ renata.mavri@guest.arnes.si \\ dr. Majda Černič Istenič \\ Univerza v Ljubljani, Biotehniška fakulteta, Jamnikarjeva 101, SI - 1000 Ljubljana, Slovenija \\ majda.cernic.istenic@bf.uni-lj.si
}

DOI: $10.3986 / G V 86104$

UDK: 338.48-44(1-22)(497.4Cerkno)

COBISS: 1.01

\section{IZVLEČEK}

\section{Podeželski turizem in socialni kapital v Sloveniji (primer vasi v Občini Cerkno)}

$V$ prispevku predstavljamo dejavnike razvoja podeželskega turizma v Sloveniji na primeru izbranih vasi $v$ Občini Cerkno. Zanimalo nas je, ali je razvoj podeželskega turizma povezan s socialnim kapitalom in ali se potencial naravnih in kulturnih znamenitosti lahko realizira preko socialnega kapitala. Preučevanje je temeljilo na analizi sekundarnih virov, pol-strukturiranih intervjujev, anketne raziskave in rezultatov delavnice $z$ nosilci razvoja podeželja na obravnavanem območju. Ugotavljamo, da naravne in kulturne znamenitosti niso zadosten pogoj za razvoj podeželskega turizma brez sodelovanja njegovih prebivalcev $z$ drugimi akterji na mikro, mezo in makro ravni.

\section{KLJUČNE BESEDE}

podeželski turizem, socialni kapital, naravne in kulturne znamenitosti, Občina Cerkno

\begin{abstract} The paper presents the case study of rural tourism development in selected villages in the Municipality of Cerkno situated in the western part of Slovenia. The main focus of the study was to found out whether the development of rural tourism is associated with social capital and whether the potential of natural and cultural attractions can be realized through social capital. The analysis was based on secondary sources, semi-structured interviews, survey and workshop with stakeholders of rural development in this area. The is missing.

KEY WORDS

rural tourism, social capital, natural and cultural heritage, Municipality of Cerkno
\end{abstract}

Rural tourism and social capital in Slovenia (an example of villages in the Municipality of Cerkno) study shows that natural and cultural heritage sites are not a sufficient condition for the development of rural tourism when the participation of local people with other actors at the micro, mezzo and macro level

Uredništvo je prispevek prejelo 10. marca 2014. 


\section{Uvod}

Med razvojne dejavnosti na podeželju poleg kmetijstva in gozdarstva sodijo tudi dopolnilne dejavnosti, na primer podeželski turizem. Pretežno neokrnjena narava nudi obiskovalcem podeželja pristne stike $\mathrm{z}$ naravo, omogoča jim športne in rekreacijske dejavnosti, okušanje ekološko pridelane hrane ter doživljanje naravnih in kulturnih znamenitosti. Podeželski turizem je za Slovenijo razvojna priložnost, ker tudi majhnim kmetijam omogoča doseganje dela dohodka in s tem ugodno vpliva na trajnostni razvoj podeželja in države (Klemenčič 2000).

V članku razvoj podeželskega turizma povezujemo s socialnim kapitalom, ki pomeni (Putnam 1993) medsebojno povezanost vaščanov in njihovo sodelovanje $z$ drugimi akterji na mikro (lokalna skupnost), mezo (občinsko območje) in makro ravni (državni in mednarodni okvir). Kot partnerji na ravni lokalne skupnosti nastopajo na eni strani nevladne organizacije in posamezniki, na regionalni ravni pa lokalna samouprava. Na državni ravni so partnerji državna uprava in strokovnjaki, ki pripravljajo analize in predlagajo razvojne usmeritve na lokalni ravni (Barbič 2005). Obenem tudi preučujemo, kako lokalni prebivalci v ta razvoj vključujejo naravne in kulturne znamenitosti. Ugodne geografske danosti ter številne naravne in kulturne znamenitosti so namreč lahko prednost pri razvoju podeželja (Carson s sodelavci 2009; Gholami, Assayesh in Alipour-Nakhi 2010).

\section{Teoretična izhodišča}

Razvoj podeželskega turizma temelji na vzporednih (horizontalnih) in navpičnih (vertikalnih) socialnih vezeh, ki se lahko ustvarjajo v posameznih skupnostih (vezivna dimenzija ali bonding) ali zunaj njih (premostitvena dimenzija ali bridging) (Jones 2005). Mandl s sodelavci (2007, cit. po Potočnik Slavič 2010) govorijo tudi o povezovalni dimenziji (linking), ki temelji na institucionalnem povezovanju javnih in zasebnih ustanov. Dosedanja preučevanja kažejo, da je premostitvena dimenzija socialnega kapitala pogosto šibkeje razvita kot njegova vezivna dimenzija, ki pa je za razvoj nujna (Johannesson, Skaptadottir in Benediktsson 2003). Različne omejitve, kot so neugodne geografske danosti, slaba cestna povezanost in nedostopnost, ovirajo podeželski razvoj in zahtevajo pomoč širše lokalne skupnosti, zato socialni kapital samih lokalnih prebivalcev ne zadostuje. Novejši raziskavi (Saxena in Ilbery 2010; Darcy in Wearing 2009) potrjujeta, da je sodelovanje lokalne skupnosti z lokalnim gospodarstvom, strokovnjaki, institucijami in obiskovalci ter povezovanje javnega in zasebnega sektorja nujna za napredek turizma v regiji, četudi gre za obmejna podeželskega območja kot sta Welsh v Angliji ali nacionalni park North Head Quarantine Station v Avstraliji.

Glede povezanosti med naravnimi in kulturnimi znamenitostmi ter socialnim kapitalom predhodne raziskave (Carson s sodelavci 2009; Gholami, Assayesh in Alipour-Nakhi 2010) kažejo, da sodelovanje lokalnih prebivalcev pri razvoju turizma poleg naravnih in kulturnih znamenitosti prispeva k razvoju lokalne ekonomije. Od lokalnih prebivalcev, vpetih v nek »dediščinski locus«, utrip dediščine, je odvisna "atmosfera « turizma, ki jo občuti gost, obiskovalec dediščine. Obenem so domačini običajno tudi lastniki zemljišč v javni rabi (na primer parkirišč, cest), zato je potrebno njihovo strinjanje, da med njimi in oblikovalci razvojne politike ter vodstvom projektov ne prihaja do problemov, konfliktov. Če se vzpostavi partnerstvo, dediščina lahko prispeva k razvoju nekega kraja.

Znanstvenih razprav o razvoju podeželskega turizma v povezavi s socialnim kapitalom v Sloveniji ni veliko, medtem ko razprav o vlogi naravnih in kulturnih znamenitosti v povezavi s podeželskim turizmom in socialnim kapitalom še ni zaslediti.

Vlogo programov celostnega razvoja podeželja in obnove vasi (CRPOV) in projektov vinsko-turističnih cest pri razvoju podeželskega turizma je proučeval Koščak (1999) na območju Krškega, v Suhi krajini in v Mirnski dolini. Pri tem je prepoznal pomanjkanje povezanosti in usklajenosti med lokalnimi skupnostmi, državnimi ustanovami ter strokovnjaki. Razloge je našel v pomanjkanju regionalnih 
in nacionalnih razvojnih usmeritev za obmejna območja, majhnih lokalnih razvojnih spodbudah in tudi v pomanjkanju sodelovanja ustreznih strokovnih institucij ter javno-zasebnih partnerstev. Za uspešen razvoj podeželja so zelo pomembni principi učinkovitosti in uspešnosti podeželja, ki so: trajnost, podjetništvo in partnerstva. Partnerstva so še posebej pomembna pri zaznavi in razreševanju konfliktov znotraj lokalne ravni ter med lokalno in državno ravnijo (Barbič 2005).

Endogene razvojne potenciale slovenskega podeželja je na primeru Zgornje Savinjske doline, Suhe krajine, Goriških Brd in Brkinov preučevala Potočnik Slavičeva (2010). Ugotovila je, da ima socialni kapital pomembno vlogo za razvoj podeželja in domnevno pozitivne učinke na posameznike in skupnosti. Socialni kapital spodbuja gospodarski razvoj, ko omogoča razpoložljivost določenih virov, ki v drugačnih okoliščinah ne bi bili na razpolago. Ob ustreznem znanju, specializaciji, razpoložljivih virih in tržnih možnostih lahko socialni kapital pomeni tržno zanimiv način aktiviranja endogenih razvojnih potencialov kmetije, lokalne skupnosti ali celotnega podeželja. Razvitost socialnega kapitala pa je odvisna od medsebojnega učinkovanja človeškega, gospodarskega in okoljskega kapitala ter specifičnih geografskih, zgodovinskih, političnih in razvojnih dejavnikov. Osnovno izhodišče je splošen družbeno-gospodarski razvoj.

Podmenik (2012) je na podlagi merjenja in vrednotenja socialnega kapitala na območju slovenske Istre ugotovil, da so najbolj opazne razlike $\mathrm{v}$ zalogah socialnega kapitala na podeželju pogojene s socialno-demografskimi značilnostmi prebivalcev - predvsem $\mathrm{z}$ njihovo starostjo in izobrazbo, ne pa toliko z lokacijo naselitve - »obmestnim« in »zalednim « tipom prebivalcev. Tako je med starejšimi prebivalci prepoznal več vezivnega kapitala, med mlajšimi in višje izobraženimi pa več premostitvenega socialnega kapitala. Ugotovil je tudi, da je slednjega kapitala v slovenski Istri manj kot na državni ravni. Z vidika (neo)endogenega koncepta razvoja podeželja, ki podpira aktivno vlogo lokalnih prebivalcev pri razvoju podeželja, rezultati te raziskave niso ugodni. Razkrivajo, da so lokalne akcijske skupine (LAS) oziroma program LEADER in delovanje nevladnih organizacij na omenjenem območju še šibko razvite in da je v prihodnje treba več vlagati v vzpostavljanje povezav med različnimi deležniki ter privabljati izobražene mlade ljudi na podeželje.

\section{Opredelitev problema in metode dela}

Na podlagi pregleda literature smo predpostavili, da je za uspešen razvoj podeželskega turizma potrebno medsebojno sodelovanje in povezovanje ljudi na vseh ravneh. Za razvoj podeželskega turizma so domnevno pomembni tudi drugi potenciali okolja, kot so socialno-ekonomske in demografske značilnosti prebivalcev ter kulturne in naravne znamenitosti njihovega kraja. Predpostavili smo, da socialni kapital lahko te potenciale udejanja. Razvoj podeželskega turizma smo opredelili kot izraz podpore vaščanov podeželskemu turizmu na ravni posameznih enot, v našem primeru izbranih vasi na območju Cerknega: Gorenjih Novakov, Šebrelj in Zakojce.

Socialni kapital smo opredelili (Putnam 1993) kot vključenost posameznikov v skupnost: pogostost neformalnega druženja (na primer obiskovanje sosedov, prijateljev), stopnja zaupanja, sodelovanje na volitvah in vključenost v prostovoljno delo. Pri tem smo razlikovali med vezivnim in premostitvenim vidikom socialnega kapitala (Johannesson, Skaptadottir in Benediktsson 2003).

Pri preučevanju smo se oprli na statistične podatke in izsledke projektov CRPOV (Lapajne Trojar in Bizjak 1999; 2001), ki so bili izvedeni na obravnavanem območju. V obdobju 2006-2007 smo izvedli poštno anketo z vsemi gospodinjstvi v vaseh Šebrelje, Gorenji Novaki in Zakojca (193 enot). Na naše povabilo se jih je odzvalo 60 oziroma 31 odstotkov gospodinjstev. Največji odziv je bil zabeležen v Zakojci (40 odstotkov), sledili so Gorenji Novaki (43 odstotkov) in Šebrelje (27 odstotkov). Na anketo so se v večjem deležu ( 65 odstotkov) odzvale ženske kot moški, poročeni (65 odstotkov), starosti skupini od 31 do 40 let ( 25 odstotkov) in od 51 do 60 let ( 22 odstotkov), prebivalci s poklicno ( 28 odstotkov) in srednjo šolo (23 odstotkov) ter redno zaposleni (47 odstotkov). $\mathrm{Z}$ anketo smo pridobili informacije 


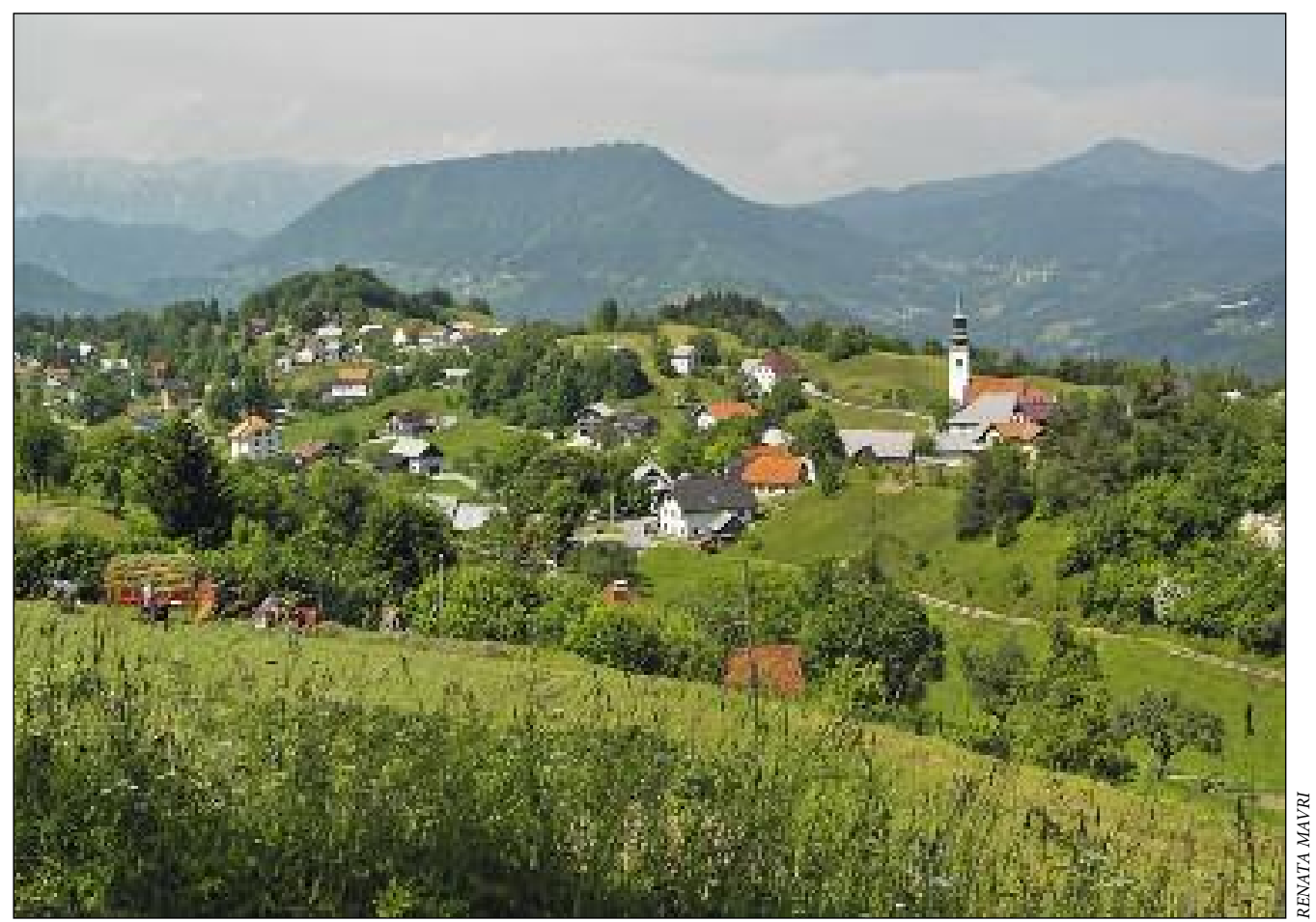

Slika 1: Šebrelje so gručasta vas s panoramskim pogledom na Alpe.

o medsebojnem zaupanju in povezanosti med vaščani pri skupnih dejavnostih na različnih področjih ter tudi informacije, povezane s podeželskim turizmom: odnos vaščanov do podeželskega turizma, stališča do obstoječih dejavnosti in oblik podeželskega turizma ter njihove morebitne načrte v povezavi z njimi.

Za ugotavljanje prisotnosti in obsega socialnega kapitala, ki presega okvire obravnavanih vasi, smo organizirali delavnico s prebivalci celotnega območja Občine Cerkno po metodi »odprti prostor « (Owen 1997). Metoda odprti prostor je moderacijska metoda, s pomočjo katere na inovativen način gradimo skupnost, krepimo odgovornost za organizacijo, omogočamo ustvarjalnost, izdelamo strateški načrt, širimo pogled, rešimo kompleksen problem, oblikujemo skupno poslanstvo in vizijo ali uvajamo spremembe. Delavnico smo izvedli na temo: »Kako v naš kraj privabiti toliko turistov, da bomo od tega lahko živeli? « Temi smo dodali še vprašanji: »Ali se v naših krajih da živeti od turizma? « in »Kaj lahko naredimo mi sami, da pripeljemo ljudi v naše hribe? « Vabilo smo poslali vsem prebivalcem Občine Cerkno z namenom, da se delavnice udeleži čim več prebivalcev, ki jih zanima nadaljnji razvoj podeželskega turizma na Cerkljanskem in ne le prebivalci obravnavanih vasi. S to metodo smo od najbolj zainteresiranih posameznikov iz obravnavanih vasi in širše dobili dodatne informacije o zamislih, načrtih in pripravljenosti za sodelovanja pri razvoju podeželskega turizma. S pomočjo te metode je mogoče tudi oblikovati skupnost s spodbujanjem odgovornosti udeležencev do skupnega dela v prihodnosti.

Rezultate ankete in delavnice smo nadgradili s pol-strukturiranimi intervjuji, izvedenimi v letih 2008 in 2011. Intervjuje smo opravili z nekaterimi lokalnimi oblikovalci razvojne politike: županom Občine Cerkno, predsedniki turističnih društev v treh obravnavanih vaseh in predstavnikoma turistične kmetije v Zakojci in Gorenjih Novakih. Leta 2011 smo v intervjuje vključili še predstavnika lokalne akcijske skupine (LAS) iz Posoškega razvojnega centra, predstavnika LAS iz turističnega društva Gorenji Novaki in predstavnika Idrijsko-Cerkljanske razvojne agencije. 


\section{Rezultati}

V nadaljevanju prikazujemo rezultate po posameznih vaseh. Rezultate povzemamo v preglednicah 1 in 2, kjer smo posameznim opazovanim kazalcem pripisali vrednosti od 1 do 3 , pri čemer vrednost 1 pomeni najbolj ugodno stanje virov (najbolj ugodne razmere za razvoj vasi), 3 pa najmanj ugodno stanje opazovanih virov (najmanj ugodne razmere za razvoj vasi). Razlike med posameznimi vrednostmi niso absolutne, temveč so relativne oziroma kvalitativne. Njihov seštevek pokaže, da imajo gledano v celoti najboljše možnosti za nadaljnji razvoj (institucionalna pomoč, turistična infrastruktura, socialno-ekonomske razmere) v Gorenjih Novakih, ki so dosegli najmanjše število točk, najslabše pa tam, kjer je bilo doseženo največje število točk, to je v Zakojci.

Preglednica 1: Izhodišča za nadaljnji razvoj podeželskega turizma v Gorenjih Novakih, Šebreljah in Zakojci na podlagi izsledkov CRPOV projektov in statističnih podatkov (Lapajne Trojar in Bizjak 1999; 2001).

\begin{tabular}{lccc}
\hline & Gorenji Novaki & Šebrelje & Zakojca \\
\hline $\begin{array}{l}\text { institucionalna pomoč } \\
\text { turistična infrastruktura }\end{array}$ & 1 & 2 & 3 \\
$\begin{array}{l}\text { sodelovanje v društvih } \\
\text { naravne in kulturne znamenitosti }\end{array}$ & 1 & 3 & 2 \\
$\begin{array}{l}\text { socialno-ekonomske in demografske } \\
\quad \text { značilnosti }\end{array}$ & 1 & 2 & 3 \\
SKUPAJ & 1 & 1 & 1 \\
& 5 & 9 & 12 \\
\hline
\end{tabular}

Preglednica 2: Rezultati ankete v izbranih vaseh v Občini Cerkno, povezanih z razvojem turizma (Mavri 2008).

\begin{tabular}{|c|c|c|c|}
\hline & Gorenji Novaki & Šebrelje & Zakojca \\
\hline uspešnost izvedbe CRPOV projektov & 1 & 2 & 3 \\
\hline $\begin{array}{l}\text { socialno-ekonomske in demografske } \\
\text { značilnosti }\end{array}$ & 2 & 1 & 3 \\
\hline prisotnost socialnega kapitala & 2 & 1 & 3 \\
\hline $\begin{array}{l}\text { zaznava možnosti ukvarjanja s podeželskim } \\
\text { turizmom na svojem domu }\end{array}$ & 1 & 2 & 2 \\
\hline $\begin{array}{l}\text { ukvarjanje s podeželskim turizmom in dopolnilnimi } \\
\text { dejavnostmi na svojem domu }\end{array}$ & 1 & 3 & 1 \\
\hline $\begin{array}{l}\text { pripravljenost ukvarjati se s podeželskim turizmom } \\
\text { in dopolnilnimi dejavnostmi v vasi }\end{array}$ & 2 & 2 & 2 \\
\hline podpora razvoju podeželskega turizma v občini & 1 & 2 & 1 \\
\hline $\begin{array}{l}\text { institucionalna pomoč občine in države vasem } \\
\text { pri razvoju podeželskega turizma }\end{array}$ & 2 & 1 & 3 \\
\hline udeležba na delavnici & 1 & 3 & 2 \\
\hline podpora lokalnih organizacij & 3 & 3 & 3 \\
\hline vključenost v LAS projekte & 2 & 3 & 3 \\
\hline SKUPAJ & 18 & 23 & 26 \\
\hline
\end{tabular}


Gorenji Novaki imajo najbolj ugodne pogoje za nadaljnji razvoj podeželskega turizma. Razvoj te vasi podpirajo oblikovalci razvojne politike, zlasti gospodarstvo (Eta Cerkno), kar potrjuje dobro razvita turistična infrastruktura (Smučarski center Cerkno). Ob pomoči CRPOV projekta je nastalo Turistično društvo Novaki, v katerega se prebivalci vasi dejavno vključujejo s sezonskim delom na smučišču in s svojimi nastanitvenimi zmogljivostmi. Vendar se anketiranci Gorenjih Novakov manj kot anketiranci Zakojce zavzemajo za intenzivni razvoj turizma, da bi lahko povečali zaslužek ali lažje prodali svoje izdelke. Svojo zavzetost za turizem so bolj pokazali z obiskom delavnice. Turistično društvo Novaki je med izbranimi vasmi tudi edino vključeno v lokalno akcijsko skupino (LAS). Intervju s predstavnikom turističnega društva in županom Občine Cerkno je pokazal, da se prebivalci te vasi zavedajo bogastva naravnih (Porezen, smučišče) in kulturnih (Partizanska bolnica Franja, novaška lok smučka) znamenitosti.

Anketa je pokazala, da sta obseg in intenzivnost socialnega kapitala največja v Šebreljah. Med vsemi izbranimi vasmi se prebivalci te vasi med seboj najbolj povezujejo (se med seboj obiskujejo, si kaj sposojajo, udeležujejo volitev). CRPOV projekti so v tej vasi prispevali k ustanovitvi Turističnega društva Šebrelje in Združenja izdelovalcev Šebreljskega želodca, vendar je za razvoj podeželskega turizma in razvoj vasi ta projekt ostal neizkoriščen. To se kaže zlasti v tem, da na območju ni turističnih nastanitev, lokalnega gostišča in tudi ne možnosti nakupa šebreljskega želodca za obiskovalce kraja. Ogled arheološkega najdišča Divje Babe, kjer je bila najdena neandertalčeva piščal, najstarejše glasbilo v Evropi, je mogoč z lokalnim vodnikom ob dogovoru s turističnim društvom. Ponudba pa ni razširjena na sprejemni center ali razstavo neandertalčeve piščali, kar bi najdišče Divje Babe približalo večjim ciljnim skupinam. S pomočjo evropskih sredstev so uredili poti v arheološki park Divje Babe in omogočili strokovno svetovanje pri zaščiti Šebreljskega želodca. Kljub visokemu socialnemu kapitalu pa je interes za podeželski

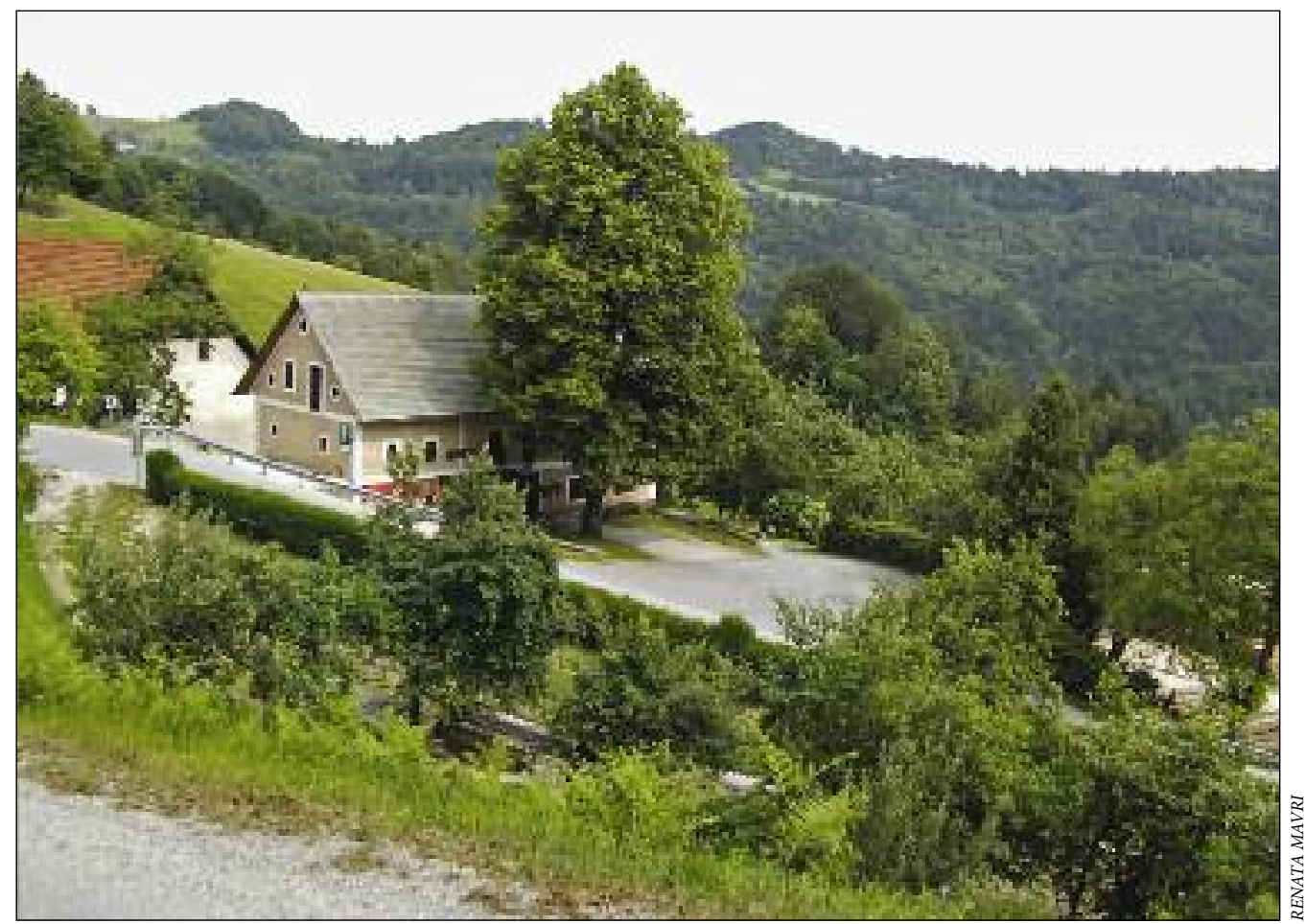

Slika 2: Gorenji Novaki so dolga, razpotegnjena vas z osamljenimi kmetijami pod smučarskim centrom Cerkno. 
turizem med prebivalci te vasi najšibkejši, saj svoje dohodke pridobivajo na druge načine v bližnjih zaposlitvenih centrih. To se kaže tudi v tem, da se anketiranci iz Šebrelj najmanj zavzemajo za intenzivni razvoj turizma. Anketiranci iz Šebrelj se sicer ukvarjajo z dopolnilnimi dejavnostmi na kmetiji, predvsem peko kruha in peciva, izdelovanjem čipk, dejavni pa so tudi pri urejanju vaškega jedra. V Šebreljah v najmanjši meri oddajajo tudi sobe in apartmaje. Tudi med oblikovalci politik je interes za razvoj podeželskega turizma te vasi izražen v manjši meri kot v Gorenjih Novakih, kar se odraža v manjših nastanitvenih zmogljivostih in gostinski dejavnosti. Šibko zanimanje prebivalcev te vasi za podeželski turizem je potrdila tudi njihova odsotnost na delavnici. Intervjuji so pokazali še, da je občinskih spodbud za nadaljnji razvoj podeželskega turizma v Šebreljah manj kot v Gorenjih Novakih, kljub številnim dejavnostim domačinov pri urejanju arheološkega parka Divje Babe. V okviru LAS-a do leta 2011 ni bilo dane nobene pobude za razvoj arheološkega parka.

Prebivalci Zakojce se že dalj časa ukvarjajo s podeželskim turizmom in dopolnilnimi dejavnostmi na svojem domu (nastanitvene zmogljivosti, turistična kmetija $\mathrm{z}$ dopolnilnimi dejavnostmi). Zaznanega pa je manj socialnega kapitala kot $\mathrm{v}$ drugih vaseh, zmanjšuje se tudi število prebivalcev. CRPOV projekti tu niso potekali. Tudi Turistično društvo Zakojce, ki se omejuje na delovanje vasi, je manj dejavno kot turistično društvo v Gorenjih Novakih. Anketiranci v Zakojci se med vsemi vasmi najbolj zavzemajo za intenzivni razvoj turizma in se strinjajo, da se čim prej razvije, ker bi imeli od tega zaslužek in bi lahko prodali svoje izdelke. Intervju je pokazal, da je bila med vsemi obravnavanimi vasmi Zakojca deležna najmanjše institucionalne pomoči pri razvoju podeželja. Kljub temu so prebivalci Zakojce z udeležbo na delavnici, zlasti ženske, pokazali veliko zanimanje za podeželski turizem. Glede kulturne dediščine je Zakojca najbolj znana po Bevkovi domačiji, glede naravnih znamenitosti pa po Zakojški

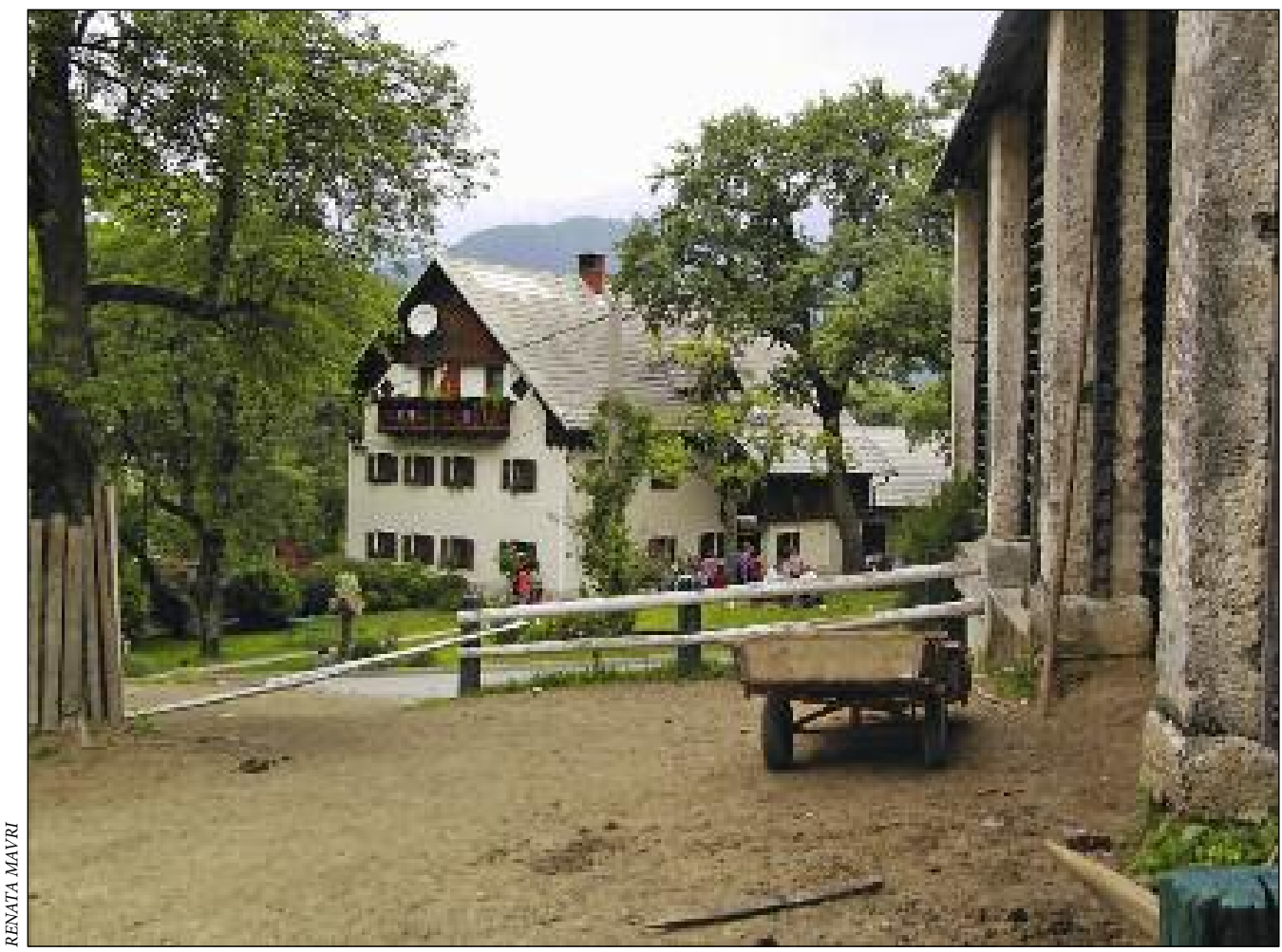

Slika 3: Turistična in izletniška kmetija v Zakojci je v osrednjem delu vasi. 
grapi, Kojci in Poreznu. Intervju je tudi pokazal, da se domačini zavedajo bogastva svojih znamenitosti in so jo sami pripravljeni urejati (Zakojška grapa). Tudi v Zakojci ni bil izražen interes za vključitev v LAS.

Delavnica v dvorani Občine Cerkno se je udeležilo 24 ljudi, ki so bili vsak na svoj način povezani s podeželskim turizmom. Iz našega obravnavanega območja so se dogodka udeležile štiri gospe in sicer tri iz Gorenjih Novakov in ena iz Zakojce. Iz Šebrelj se delavnice ni udeležil nihče. Nasploh so se ženske udeležile delavnice $\mathrm{v}$ večjem številu kot moški. S tem so pokazale večji interes za ukvarjanje s podeželskim turizmom in s svojo prisotnostjo nakazale svoj prispevek k ustvarjanju socialnega kapitala v svoji vasi in Občini Cerkno. Podobno kot ugotavlja Černič Isteničeva (2003; 2006), tudi ženske v Občini Cerkno s svojo prisotnostjo in delovanjem kažejo željo prispevati k stabilnosti družbenega in ekonomskega življenja na podeželju.

Preučevanje povezav socialnega kapitala ter naravnih in kulturnih znamenitosti je pokazalo, da prebivalci Gorenjih Novakov z ohranjanjem in krepitvijo kulturne identitete ter dejavnim medsebojnim povezovanjem ustvarjajo možnosti za razvoj podeželja. Povezujejo se tudi z mednarodnimi društvi (starodobno smučanje), občino, gospodarstvom in različnimi strokovnjaki. Tako lažje pridobivajo finančna sredstva. Geografske danosti in razvoj smučarskega centra predstavljajo možnost nadaljnjega razvoja turističnih dejavnosti. Nasprotno v Šebreljah kljub prepoznanemu socialnemu kapitalu v sami vasi, institucionalni pomoči, bogati kulturni in naravni dediščini, ugodnim socialno-ekonomskim in demografskim pogojem ni interesa za razvoj turizma. Povezovanje vaščanov z drugimi društvi, občino in državo izven lokalne skupnosti je šibko. Arheološki park Divje Babe ostaja neizkoriščena priložnost. Med vsemi vasmi pa Zakojci najbolj primanjkuje povezovanj med prebivalci in partnerstev s širšo skupnostjo. Ovira razvoju so tudi neugodni socialno-ekonomski in demografski dejavniki. Za vlaganja in investiranje v lokalno ekonomijo bi bilo nujno oblikovati partnerstva tako s sosednjimi lokalnimi skupnostmi, društvi kot tudi z različnimi strokovnjaki.

Ovire za razvoj podeželskega turizma pa se ne kažejo le na strani vaščanov omenjenih vasi, temveč tudi na strani drugih akterjev. Da je občina premalo usmerjena v razvoj podeželskega turizma, nam pove dejstvo, da še nima izdelane »strategije trženja turizma«. Na svojo pobudo, kot je vintervjuju povedal njen župan, je sicer ustanovila lokalno turistično organizacijo (LTO), vendar je tako finančno kot kadrovsko ni zmožna podpirati. Na skromno zavzetost Občine Cerkno za razvoj podeželskega turizma so opozorili tudi udeleženci delavnice in sicer, da ta premalo sodeluje z gospodarstvom, ki je pri tem bolj dejavno (smučarski center). Intervju s predstavnikom Posoškega razvojnega centra, upravljavca LAS-a za razvoj, ki vključuje tudi Občino Cerkno, pa je pokazal, da je pri razvoju podeželskega turizma največji problem pomanjkanje kadra, ki bi lahko dejavneje delal z lokalnim prebivalstvom na terenu (delavnice, predavanja). Naše preučevanje je tudi pokazalo, da je bilo delovanje lokalnih organizacij, kot so Idrijsko-Cerkljanska razvojna agencija (ICRA), LTO in občin (Idrija, Cerkno) v zadnjih letih v okviru LAS-a za razvoj, usmerjeno predvsem v razvoj podeželja in lokalne proizvode (kmečka tržnica, idrijska čipka), manj pa v razvoj turizma ter naravnih in kulturnih znamenitosti.

\section{Sklep}

Preučevanje v izbranih vaseh v Občini Cerkno je potrdilo, da niti socialni kapital na ravni skupnosti, niti naravne in kulturne znamenitosti niso zadosten pogoj za razvoj podeželja in podeželski turizem, če se prebivalci pri tem ne povezujejo tudi z oblikovalci razvojne politike in institucijami, strokovnjaki, ter če ni udejanjenih načel »od spodaj navzgor« in »od zgoraj navzdol«, kot je ugotovila že Barbičeva (2005). Naš primer je potrdil, da je pogoj za razvoj podeželskega turizma premostitveni socialni kapital. Podobno so ugotavljali tudi Johannesson, Skaptadottir in Benediktsson (2003) ter Jones (2005) in Potočnik Slavičeva (2010). 
Ugotovili smo, da se na obravnavanem območju kljub močnemu vezivnemu socialnemu kapitalu in danim potencialom (primer arheološkega parka) niso uveljavili projekti, ki bi bili usmerjeni v ohranjanje in izboljševanje naravnih in kulturnih znamenitosti. Pokazalo se je, da so projekti, namenjeni ohranjanju in razvijanju naravnih in kulturnih znamenitosti, zahtevni do te mere, da jih lokalne skupnosti same, to je vasi, niso sposobne same izpeljati. Tudi občinam in razvojnim agencijam, ki se jim v zadnjih letih nalaga vse več obveznosti in odgovornosti (v preteklosti v domeni države), so ti projekti preobsežni zlasti v finančnem smislu. Pri pridobivanju evropskih sredstev so te neuspešne ravno zato, ker so premalo vključene $\mathrm{v}$ regionalno sodelovanje in povezovanje $\mathrm{z}$ državnimi institucijami. Zato bi bilo nujno, da se v prihodnje bolj povezujejo navzven in se zavedajo pomena horizontalnih in vertikalni socialnih vezi. Obenem pa bi morale občine in razvojne agencije tudi bolj upoštevati interese in podjetniško naravnanost lokalnih prebivalcev in razpoložljiva sredstva namenjati čim širšemu krogu zainteresiranih.

\section{Viri in literatura}

Barbič, A. 2005: Izzivi in priložnosti podeželja. Ljubljana.

Carson, D., Prideaux, B., Coghlan, A., Taylor, A. 2009: Heritage as a motivation for four-wheel-drive tourism in desert Australia. Journal of Heritage Tourism 4-3. London. DOI: 10.1080/17438730802691707

Černič Istenič, M. 2003: Potential of farm women in Slovenia for rural development. Perspektive žena u obiteljskoj poljoprivredi i ruralnom razvoju. Poreč.

Černič Istenič, M. 2006: Farm women in Slovenia. Rural Gender Relations: Issues and Case Studies. Wallingford.

Darcy, S., Wearing, S. 2009: Public-privat partnerships and contested cultural heritage tourism in national parks: a case study of the stakeholders views of the North Head Quarantine Station (Sydney, Australia). Journal of HeritageTourism 4-3. London. DOI:10.1080/17438730802433852

Gholami, S., Assayesh, H., Alipour-Nakhi, A. 2010: The study of tourism geography in rural areas of Noushahr City of Mazandaran Province (Iran): the case of Balade KojourVill. JournalAmerican-Eurasian Journal of Agricultural and Environmental Science 7-3. Teheran.

Johannesson, G., Skaptadottir, U., Benediktsson, K. 2003: Coping with social capital? The cultural economy of tourism in the North. Sociologia Ruralis 43-1. Oxford. DOI: 10.1111/1467-9523.00226

Jones, S. 2005: Community-based ecotourism. The Significance of social capital. Annals of Tourism Research 32-2. Philadelphia. DOI: 10.1016/j.annals.2004.06.007

Klemenčič, M. 2000: Turizem - rešitelj slovenskega podeželja. Turizem - razvojna možnost podeželja. Ljubljana.

Koščak, M. 1999: Preobrazba podeželja ob slovensko-hrvaški meji. Doktorsko delo, Oddelek za geografijo Filozofske fakultete Univerze v Ljubljani. Ljubljana.

Lapajne Trojar, A., Bizjak, M. 1999: Anketa CRPOV KS Šebrelje. Lokalni podjetniški center občin Idrija in Cerkno. Idrija.

Lapajne Trojar, A., Bizjak, M. 2001: Anketa CRPOV KS Novaki. Idrijsko Cerkljanska razvojna agencija. Idrija.

Mavri, R. 2008: Vloga socialnega kapitala v razvoju turizma v izbranih podeželskih skupnostih. Magistrsko delo, Biotehniška fakulteta Univerze v Ljubljani. Ljubljana.

Owen, H. 1997: Open Space Technology. San Francisco.

Podmenik, D. 2012: Preučevanje socialnega kapitala na podeželju: študija primera Slovenske Istre. Raziskave in razprave 5-2. Nova Gorica.

Potočnik Slavič, I. 2010: Endogeni razvojni potenciali slovenskega podeželja. GeograFF 7. Ljubljana. Putnam, R. D. 1993: Making Democracy Work: Civic Traditions in Modern Italy. Princeton.

Saxena, G., Ilbery, B. 2010. Developing integrated rural tourism: Act or practices in the English/Welsh border. Journal of Rural Studies 26-3. Oxford. DOI:10.1016/j.jrurstud.2009.12.001. 


\section{Summary: Rural tourism and social capital in Slovenia (an example of villages in the Municipality of Cerkno)}

(translated by Majda Černič Istenič)

Rural tourism is development opportunity of Slovenian small farms to prosper and sustain. Collaboration between local community, local economy, experts, institutions and visitors as well as integration of the public and private sectors is supposed to be important for development of rural tourism. Furthermore, it is supposed that well preserved natural and cultural heritage can additionally contribute to the development of tourism on farms. Moreover, social capital has an important role in development of countryside and supposedly affects individuals and communities positively, because it supports better social interaction and increases the probability of successful employment and entrepreneurship. As previous studies show development of social capital depends on the mutual effect of human, economic and environmental capital and specific geographic, historical, political and development factors. Local societies may be an important factor of local development and a measure for the development of social capital. In order to deal with heritage thoroughly and to include it in regional development it is necessary to account for conservation of nature as well as its social component i.e. cultural value, which is subjectively valued, since it defines our relationship to heritage.

Through the analysis of secondary sources, semi-structured interviews and surveys and the results of the workshop 'Open Space' with the actors of rural development, the above mentioned elements of rural tourism development in the case of selected villages in the Municipality of Cerkno are presented.

We have found out that among the selected villages, best conditions for development (institutional support, touristic infrastructure, socio-economic conditions) are in Gorenii Novaki, followed by Šebrelje, with Zakojca in last place. The development of Gorenji Novaki is supported by policy makers, especially economy. The inhabitants of this village were active in touristic society's activities as well as in the Local Action Group (LAG). They also have shown their enthusiasm for tourism by attending the workshop. Likewise they are aware of the value of natural and cultural heritage. The size and intensity of social capital is the biggest in Šebrelje as the residents of this village are the most cooperative. In this village the integrated rural development and village renewal projects (CPROV) contributed to the establishment of the touristic association and the Association of producers of Šebrelje stomach, but this project remained untapped. This is particularly evident from the lack of touristic accommodations, non-existent local boarding house and tourists being unable to buy Šebrelje stomach. Also the capacities of sight-seeing tour to nearby archaeological park Divje Babe are not utilised. The interest for rural tourism development in this village is weaker than in Gorenji Novaki as well as there are less municipal initiatives presented for further development of rural tourism despite numerous inhabitants' activities related to Divje Babe archaeological park. Inhabitant's scarce interest in tourist activities was also evident from their absence at the workshop. One of the reasons for small interest in rural tourism are good employment possibilities in the nearby valley. The other situation holds true for inhabitants of Zakojca who have been involved in rural tourism and supplementary activities at their homes for quite some time. In comparison to other villages in Zakojca a lower level of social capital and faster population decline has been detected. There were also no CPROV projects in action there. Even the tourist association is less active than this is the case in Gorenji Novaki. The interview with tourist association representative has shown that among all selected villages, Zakojca had received the least institutional support for rural development. However, the residents of Zakojca, especially its female part, proved their interest in rural tourism by taking part in the workshop. The locals have been aware of the value of their heritage and have been willing to organise themselves to contribute to the development. However there was no interest shown regarding participation in LAG.

Studying the linkage of social capital and natural and historical heritage has shown that the residents of Gorenji Novaki create opportunities for rural development through maintaining and reinforcing cultural identity and active mutual cooperation. They cooperate with municipality, busi- 
ness enterprises and various experts as well as international associations, which in turn allow them to gain financial sources more easily. Geographic factors and development of the Ski Centre represent an opportunity for further development of touristic activities. On the contrary, in the case of Šebrelje a connection with other associations, the municipality and the state outside the local community is weak. But considering all three villages, Zakojca has the biggest shortage of connections between the residents and partnerships with the broader community.

Barriers which prevent the development of social capital are not apparent only in the case of inhabitants but also in the case of other actors. The municipality has not yet created a strategy for marketing tourism, which demonstrates its weak interest in rural tourism development. While it have founded the Local Tourist Organisation (LTO) on its own initiative, as the mayor said in an interview, but it is not able to support its staff financially due to oversized expenditure. The participants of the workshop have also warned about the modest commitment of the Municipality of Cerkno. They pointed out that it does not cooperate with the economy enough (e.g. Ski Centre). An interview with the representative of the Posočje Development Centre, manager of the development sector for LAS, which includes the Municipality of Cerkno, has revealed that in the case of rural tourism development, the biggest problem is lack of human resources (workshops, lectures). Our field study have also shown that cooperation of local development organisations like Idrijsko-Cerkljansko Development Agency (ICRA), LTO in municipalities (Idrija, Cerkno) as a part of LAS was in recent years more oriented towards rural development and local products (rural fair, Idrija lace) but less towards tourism development as well as natural and cultural sights.

Our case study of the three selected villages in the Municipality of Cerkno has confirmed that neither social capital on community level and neither natural and cultural heritage are sufficient for rural development and rural tourism, if the locals do not also link-up themselves with the policy makers and institutions and if there are no implemented principles "from bottom to top « and "from top to bottom«. The precondition of the development of rural tourism is mainly bridging social capital.

Additionally, the study showed that the projects which are meant to preserve and develop natural and cultural heritage are too challenging for local communities to handle on their own. They are too demanding especially from the financial point of view even for municipalities and development agencies, which in recent years have been receiving additional obligations and responsibilities that in the past were in the domain of the state. They were unsuccessful in gaining financial support from European Union because they were not involved in regional cooperation and linking with governmental institutions enough. Therefore, it is crucial for them to connect more in the outward direction and be aware of the importance of horizontal and vertical social ties. At the same time, municipalities and development agencies should take note of interests and business minded local residents more and devote more resources to a wider circle of stakeholders. 